\title{
An Ironic View on a Convoluted Reality: Part B
}

\author{
Amos Avny \\ Omnidev International, Yehud, Israel \\ Email:amosav@smile.net.il
}

How to cite this paper: Avny, A. (2021).

An Ironic View on a Convoluted Reality: Part B. Open Journal of Philosophy, 11, 194-210.

https://doi.org/10.4236/ojpp.2021.111015

Received: December 27, 2020

Accepted: February 23, 2021

Published: February 26, 2021

Copyright $\odot 2021$ by author(s) and Scientific Research Publishing Inc. This work is licensed under the Creative Commons Attribution International License (CC BY 4.0).

http://creativecommons.org/licenses/by/4.0/

\section{(c) (i) Open Access}

\begin{abstract}
The feeling of uncontrolled confusion that envelops the Western world of today was the main reason for working on this thesis. The current COVID-19 pandemic came just in time to increase this sense of obscureness. This essay follows the first part of the work that referred to the behavior issues. Thus, the Author calls for deepening the study of individual inner-self as the key for better understanding human-beings behavior. For attaining this goal, it is suggested to involve some techniques taken from the Quantum Theory in Brain Research. After discussing the issues of naming and labeling the Author explains why today, one word cannot describe a whole act, event, or capacity and why a more descriptive term is required. For this purpose, the Matrix Model could be of great help. Further the complex of human inner-self, its urges, drives and motives are discussed, explaining the complicated influence of internal and external factors on behavior. Then the meaning of Self-esteem and Self-confidence and their influence on the person's conduct is examined. Finally, mediocrity, its origin, appearance, practices and threats are explored. The essay ends with a call to reconstruct a revised social order, based on solidarity, togetherness and human compassion.
\end{abstract}

\section{Keywords}

Inner-Self, Mediocrity, Quantum Theory, Social Awareness, Post -Modern Confused Reality, COVID-19 Pandemic

\section{Part A: \\ Reflections on Behaviors and Conducts \\ Part B: ${ }^{1}$ \\ The Inner-self Mysteries and the Origin of Mediocre}

\section{Introduction}

"Life, as we find it, is too hard for us; it brings us too many pains, dis${ }^{1}$ File: An Ironic View 21, Chap B, Final 65. 
appointments and impossible tasks. In order to bear it, we cannot dispense with palliatives measures ... There are perhaps three such measures; powerful deflections, which cause us to make light of our misery; substitutive satisfactions, which diminish it; and intoxicating substances, which make us insensitive to it." (Sigmund Freud, Google Search)

While discussing, in Part A, people's behavior, we want emphasizing that for us the single human-being, the common person, the day-to-day citizen, are the real and basic cornerstones of all human endeavors. This focus on individuals is also supported by Sigmund Freud ${ }^{2}$ who argues that people usually "underestimate what is of true value in life." Unfortunately, not too many writers accepted this point of view. All religions naturally emphasize the Divinity's supremacy while preaching for an absolute submission and total obedience to His Commands. They argue that God always knew better, and people should permanently worship Him.

Following the Industrial Revolution, at the $18^{\text {th }}$ and $19^{\text {th }}$ Centuries, when novel economic-political ideologies, Capitalism and Socialism/Communism evolved and urge for power, they disregarded and dismissed the common people's interests and the individual's needs. Capitalists perceive human-beings as a kind of raw-material, an instrument for making money. Socialists perceive individuals as building blocks for building their utopian wishful new social organizations. It might be true arguing that in fact, the academy was the first major institution that had begun studying this issue seriously. Arts might be the second field that referred to individuals, since they basically manifested the artistic point of view. The study of a human-being as a single individual was promoted in the late $19^{\text {th }}$ century as a part of the study of psychology and other closed fields. Here, also the decision was made mainly for medical reasons and in favor of the scholars and their quest rather than common people request.

Our perspective is different. We intend to look for a true, authentic and genuine meaning of proper, advanced and responsible individualism. This type of revised individualism should be suitable and able to act and perform at the chaotic, Post-modern $21^{\text {st }}$ Century. We try finding out the real and proper purpose of "We the People." ${ }^{3}$ We reject the Capitalist presumption that men were born to make money, or if they cannot do it by themselves, they should assist others to do it. Similarly, we reject the Socialist perspective that perceives individuals as built-in components of society.

Our argument is quite clear and simple. We claim that all people, all over the globe, of all walks of life and of all ages, even if they are not equal, still want first and foremost, to be Happy, Joyful and Prosperous, as much as it is possible. This is the ultimate goal of every human-being in every place on the face of the earth. Although this goal is self-explainable, it is elementary and easy to be agreed upon, it is still, far from being attained. As a lesson learnt from the ${ }^{2}$ Sigmund Freud (1856-1939), An Austrian Jewish neurologist and the founder of psychoanalysis. ${ }^{3}$ The Opening phrase of the American Constitution's Preamble. 
COVID-19 plague, we learnt that people should be acquainted and familiar with this goal from their early days. The kindergarten is the proper place for teaching youngsters that despite of their variation they should urge to attain this common and great goal. For promoting this idea and building a supportive community, they should act together, wisely and consistently, rather than competing and disturbing each other. Thus, all public and private initiatives should be aware of this aspiration and must maximizing their efforts for attaining common rather single interest.

However, for facilitating, teaching and training young people to embrace a more positive conduct, there is no choice, but to enter into their deep, concealed inner-self. Although many external effects are good, but they are not effective enough for affecting the individual's intimate inner-self. That is the reason for turning now for examining the Human-Inner-Self.

\section{Reasons for Involving Quantum Theory in Brain Research}

Human inner-self is a very complicated, confused, impulsive and ambiguous Organ or a Capacity. That is a good reason for confusing psychologists and perplexing many others. This organ contains a bunch of multi-direction vectors that move to contractionary directions, in fluctuating energies and dialectical frequencies. In the past, following the Modernity school of thought, their definition was relatively easy. Modern modes of researching were based at the past on the binary approach, that assumed that solutions are simple, either positive or negative, either good or bad. So, mostly, vectors or traits, were divided into two definite types of conduct, high or low, positive or negative etc. The moves on the vectors and the energy flows, consistently run from one pole to the second one in a very queer order. This description seemed simple for researchers and easy for presentation. However, this formal binary separation does not fit reality and does not reflect real behavior, as it is perceived at present, at the Post-modern era of the $21^{\text {st }}$ Century.

The advanced, Post-modern approach, have a different point of view. It perceives the inner-self as a complex construct of traits, features and stimuluses that simultaneously move in all directions, attracted and is driven by different instincts, impulses and wishes. These groups of characteristics, run through lines of nerves (mostly not straight ones) or channels of energy, which run between two poles. It seemed like a semi-conventional unit of electricity. The inner-self poles represent all the capacities of a given trait, Good or Bad, etc. The main features are characterized by similar behavioral patterns

The justification for importing ideas, techniques and practices, taken from Quantum Theory, to Brain research and Mind inquiry, evolves from the fact that many inquiries deal with examining and studying boxes, capsules or bodies, which contain a very large number of mysteries and obscurities. For enhancing understanding the complicated environment exists there, we offer hereafter a simple, or maybe an over simplifying description of the human decision-making box. It is similar to the quantum box. Brain or mind seemed to be boxes where 
undefined tiny masses and energies, go around spontaneously, constantly change directions and permanently are in a move. Thus, we believe that a growing interdisciplinary research effort, may yield better benefits for all.

Because, the Brain little thinking capsule, contains a whole world of mystery, it is fair assuming that this is the Divine Sparkle, which, according to some Holy Books dwells in most human-beings. Understanding human mind sometimes seems as exploring multi-dimensional Physical or Space-related phenomena. Using similar research methods seems, therefore, to benefit all participants. The concealed rules that lead miniscule energies within the Atom environment, the less-discovered energies that run our Galaxy and the mysterious nervous instincts that steer our behavior, may be similar. It makes therefore sense, that the use of the Quantum Theory may help. It might be very inspiring observing human wishes, desires and hopes as miniscule amounts of sparkling energy, which spontaneously move from point to point. When human rational and emotional urges or wishes, would be able to be converted into energy glittering observable bodies Psychology will make a significant step forward. Similarly, let us hope to see the time, when Psychologists will learn little on the Quantum Theory, while Physicists will acquire some know-how on human mind, soul and inner-self. Thus, we hope, together they may bring salvation to earth. A more detailed discussion on this point is presented in Section 2 of Part A, of this work, now in print.

\section{Personality Is Demarcated by Names and Titles}

Since Name giving is first official act, symbolizing the social recognition of a new-born to be a legitimate member of society, we start our discussion with examining the meaning of names.

Every human-being has a First Name, for demarcating his/her legitimate existence in the universe. Usually, first names are given by the baby's parents for symbolizing something, a person, a hope, a desire or a belief. Most people follow this indication while some even run their life in accordance with this parental mission. Those who disagree or reject the parental calling usually change their first name.

Many have also Second and Third names. By this act they wish to indicate or show the linkage of the new-born to the extended family or the authentic group. People, in general, tend to preserve and uphold their second name since that defines their family, their social affiliation and reenforces their whole sense of belonging. Some, like the indigenous Americans, use other methods for granting names, but as they are very small minorities, we disregard them here. The Nazis, in the Second World War, have rejected both first and second names. They have tattooed figures on the concentration camps detainees' arms, for demonstrating their negative, unhuman and insulting approach to the miserable captives. Resulting from this terrible experience, all types of democracies reject and deny using figures instead of names, when referring to human-beings.

On the other hand, because of the deep sense of human individualism, the US 
principally declines, up to now, the introduction of an official system for numerical identification. Thus, official identity number, for demarcating people, does not exist in America. They use the Social Security Number (SSN) as a replacing technique.

The Third, Fourth and Fifth Label describing the Ethnic, Religious or National affiliation of a person. This type of inquiry seemed in the past, by many, as "politically incorrect." They are mostly those who like playing with the idea of personal globalism, World citizenship and a globe without political boundaries. This tendency in retrospect, might be attributed to two factors. The first one was the understandable negation of, the contradiction to, and reservation from, nationalism in principle, resulting from World War Two's terrible experience. The second cause for such a wrong global approach, sprang from a naïve or even little understanding of human personality. We know at present, how important is the sense of belonging and how critical is it for driving people forward and upward. National Pride, symbolized by the Hymn and the Flag is always a very important spiritual reward in many Sport event, Military ceremonies and outer-space projects. We know today quite well, that people find themselves lost and forlorn when they face humongous Nature's intimidations, man-made challenges or disasters. In these occasions they look for human supporting networks and a national solidarity envelope for assisting them overcoming these traumas. At the $19^{\text {th }}$ Century, at the Colonialism era, being a "British Subject" or a "French Citizen" were, by themselves a security envelope for many explorers in Africa and other Less-Developed areas.

Nationalism became more legitimated in the 1980's, towards the collapse of the Soviet Empire and the end of the Cold War. At that time affiliation with an ethnic group or a similar organization was better accepted by the public. This change happened since all recognize people's need not to stay alone and wanted to be a part of some social affiliation. That feeling saves them from anonymity, while strengthening their self-esteem. Consequently, the feelings about World Citizenship turned toward protection of Earth, Climate and Nature etc.

A similar move experienced the need to address or describe a behavior or a conduct. The former Modern custom of addressing these phenomena by one name or term, does not fit any more, to the Post-modern convulsive time. As previously mentioned, behavior is a product of many influencing elements like, genetics, internal drives and motives, external impacts of the environmental, education, family, religion, ideology and so on. The use of the proposed Matrix Model just assists in understanding how complicated is the wish to exactly portrays or describe the profile or the form of a behavior or a conduct.

Now the platform is ready for discussing the internal deep motives that carve and shape the individual's inner-self and personality.

\section{Human Inner-Self Is Structured of Urges, Drives and Motives}

A complex of overwhelming number of linkages, direct and indirect contacts, 
and bunches of senses, impulses and instincts, is what creates the genuine personality, the Individual's inner-self. Although some of them are exposed while other are concealed and hidden, all of them steer and direct human behavior. Basically, they all dwell at the Mind, but many tend to place them in the Heart, claiming that this is the home of feelings. Some of major senses are further detailed.

\subsection{Genetics \& Education That Craft and Shape the Inner-Self}

The discourse on who is responsible for the construct, the form and the nature of a human being run for many years. One school, mostly Marxists, held that the external surroundings, the production system and education in particular, could reshape and restructure the individual's nature and character. Or, as Marx taught, "changing the ownership of production means will change society, and by so doing the renewed relationships will craft a new type of a person, a better and more productive individual' (Marx Karl). The Soviet regime had followed this teaching while believing that they will be able to develop a New Soviet Person. The collapse of the Soviet Empire, and the meeting of its citizens with the Western world, clearly proved the shortcoming of such an unrealistic claim.

On the other hand, many Western Conservative schools rejected the above presumption and claimed that most human traits emerge from genetic and ethnic origins. This argument led to a ridiculous opinion claiming that people should choose their parents in order to ensure their future advancement and achievements. History teaches us of how erroneous are all these perceptions. Past history is full with examples and cases telling on children of all types of upper-class families that deteriorated and joined crime and semi-crime groups. Less-fortunate drug-users, homeless and similar deprived groups, are full with similar miserable cases. Thus, family, social class and genetics alone, do not ensure better conduct, prosperity and pleasant future.

The unsolved issue created by the above two contradicting approaches lead us to offer a third perspective, a complementary one. This perspective embraces the positive aspects of each school. It firmly argues that, internal Genetic and external Education and Environmental variables, all participate in crafting and building today's individual's personality. The fight against the Coronavirus plague, as well as previous emergency situations taught us that collaboration and joint ventures almost always, attain better and more appropriate results than a solitary or competitive mode of operation. This maxim works for large operations as well as for minute cases. It assists in better understanding human personality and inner-self.

In concluding this section, we find it helpful remembering that human-being is a very complicated creature. In spite of all analyses and efforts understanding it, human inner-self is still an intertwined complex of dreams, hopes, instincts and behaviors. The following four features, dialectical behavior, qualitative nature, less-understandable patterns, and a combination of instincts 
and urges, are together a combined product of genetic and education impacts. This is the basic common ground for daily performances. In addition to these common characteristics, exists also a vast range of internal specific drives and motives that eventually crafts and shapes the individual's genuine personality.

\subsection{The Meaning of Self-Esteem and Self-Confidence}

Self-esteem, Self-confidence and Self-interest are perceived as the basic, more affecting and critical building-blocks of the inner-self. They are the key and the primary factors of human-beings' personality. High self-esteem may bring people to the Moon while lack of self-confidence may drag them to Hell. Unfortunately, only few dare claiming that a lack of self-esteem and a low self-confidence are the parent of evils, devils and other terrible horrendous disasters, that occurred in the world. Those who lack a self-sense of worth, eventually do not respect others. Simply saying, they do not know the true meaning of these terms. By digging deep in people's soul one can find out that worst features initiated in a sick, undeveloped or unsecured inner-self. These are individuals with low or unsecured personality.

Although this is a delicate matter that may conflict with the Political-correctness perception, we have to admit that many bad and cruel actions emerge from low self-esteem and inferiority feelings. Good and positive deeds emerge from self-confidence and high sense of worth. In other words, one should love himself in order of being able to love others. People with inferior sense, are among those who frequently behave terribly. So, when facing a crime or another unspeakable case, it is advisable to dig deep in the offender's soul for finding the sick inner-self for reasoning. Generally speaking, sick family relations and wrong parent conduct, may increase and deepen the sense of inferiority and the feeling of low self-esteem. Having an uncertain personality, exaggerated hesitancy and over fearing, signify that something is ill in the person self-esteem. Some kind of pride and dignity are required for building and developing a free, respectful citizen in our democracies. Little, can hardly replace these types of self-esteem. Unfortunately, many who have them, exploit and abuse them up to an unbearable point. Finding the proper and rightful balance between the participating vectors is among the inspiring roles of every social activist or a political leader. However, the political-correctness approach tends to run away from these issues, because of the fear from deep digging in social conducts and human behavior.

\section{Problems of Good, Bad and Their Fallacies}

Defining or explaining what is Good or Bad is complicated. The computer "Word" software, lists the following words as synonym for Good: Blameless, Decent, Moral, Noble, Respectable Upright, Virtuous and Worthy. Even if this list represents all options, we assume that some will add or change it. Similar is the case with the word Bad, where the synonyms are: Evil, Wicked, Corrupt, 
Immoral, Depraved, Cruel and Shameless. However, the problem, in essence, is not with the definition, it is much more critical, since it refers to the insufficient understanding of these phenomena. First, we claim that part of the valued expressions, are time, culture and geographic oriented terms. Preferring family members, relatives or siblings is perceived in the West as corruption whereas in Africa, it is among the elder brother's first duties and obligations. In the Far East some people eat dogs, while in the West they are beloved pets. Thus, many examples exist indicating the relativeness of many moral values. In this case, also, like in other similar contradictions, the past/former years definition, does not fit to the new reality of the Post-modernism.

Although a loud and clear separation, between good and bad was installed at the early days of monotheism in the Holy Bible for example, it was done because the forefathers wanted to fix it deep in the national heritage. The monotheistic religions justified their existence by the claim that they help people to find the proper way, to be good and to distance themselves from evil. Since the development of this argument had started thousand years before Einstein's Relativity Theory, everybody accepted and embraced it. It was, and still is, much easier to pose two opposing options, than philosophizing about unclear definitions or boundaries. Most common people, in the past, were simple and they pursued simple arguments. The religious Founding Fathers, who were very smart and sophisticated, have known exactly, how to build up their steering position and commanding status. With this talent and capacity, they were able convincing their followers about the need of listening in addition to following and worshiping the Mighty Divine. The built-in contradiction between good and bad was just an assisting leverage for empowering religious and traditional leaders of the Past. Moreover, in order to maximizing the effect on, and the rewards for religious obedience, much was promise to the orthodox followers. Heaven and $\mathrm{Pa}$ radise were promised to the candid worshipers, while the infidels were sent to Hell.

The above dualistic approach, which does not exist in nature, and is a creation of human mind and imagination, came for deepening the understanding and reinforcing common people's faith. So, helping others became over the years, a whole concept, a philosophical perception, and a major guidance for good life. Expressions like: Short or Tall, Fat or Slim, Bright or Dark, Strong or Weak, have no morals and a little meaning when referring to engineers, professors or medical doctors. Thus, using the dualistic method in Social Sciences, for categorizing people by only two extreme poles, eventually says little and has a limited meaning.

On the other hand, when introducing the dualistic method, termed recently as the Digital or Binary techniques, into Physics, Mathematics and other technological disciplines it significantly added a better understanding and enables a more sophisticated use. The point we want making here is as follows: At the Post-modern era and particularly in Social Sciences, when so much is unknown, time comes for replacing the dualistic categorization by a more ap- 
propriate method of sorting or describing people. We may compare this move to the advancement in arithmetic, from the elementary Linear Algebra to the advanced Calculus Mathematics. Straight-line relations do not exist in Nature as they do not occur in human soul and mind, appropriate techniques, therefore, should be used for improving inquiry and understanding.

The Coronavirus pandemic helps us in this point, by demonstrating how much, still is unknown. How many unpredictable surprises, most of them unpleasant ones, may appear in the coming years? They may be very dangerous or less, but will reveal new and unpredictable phenomena.

Behavior study invested much energy in finding ways for categorizing people. The main reason for that project, in addition to the academic curiosity, was the growing demand for a mix of qualified employees. Although, the demand began after World War Two, when industries sought skilled employees, it continues up to our days. Advanced ways, for categorizing candidates for different missions still are of great demand.

The main mistake lays in the desire to describe or label an individual by a single word. By definition, almost every human-being is a very complex creature, who rarely could be described by one word. Some even argue that the Divine Spirit rests in every single person, because the Bible says that "God created man in his own image" (Holy Bible).

On the other hand, the American Constitution's authors, when discussing the necessity of a constitution, argued that "human-beings are not angels, they are living creatures." meaning, they may make errors and mistakes. Naturally, they have good and bad habits, nice and not so nice behaviors, which, frequently are mixed and happen to appear simultaneously. All people need, therefore, to have some legal framework in which they will be able "to form a more perfect Union, establish justice" and so on. ${ }^{4}$

Departing from similar harbor leads us to look for a better and more advance method for describing and presenting living creatures and complex human-beings like Adam and Eve.

We have proposed in previous chapter, a revised descriptive method, which placed couples of descriptive expressions, personal qualifications and different characteristic traits, along a straight line or a double-poles Vector. One expression of a feature, lays at one end or pole, while the second one, rests on the other end. For example, the Good-Bad couple will be placed on a two poles vector. The position on that vector represents a certain value or the relative weight of the examined trait. It could be measured on a 1 to 10,1 to 7 or 1 to 5 scales. 1 represents the very low value and 10, 7 or 5 represent the very high levels. When all these measuring lines are combined together the result looks really like a non-orderly bunch of intertwined characters.

Referring to the Inner-self, it should be understood that there is no meaning to the phrase good inner-self or even bad character. Human limbs, legs, hands,

${ }^{4}$ The Preamble of the US Constitution. 
heart or even mind have no moral or ethical value. They may physically be sick or defected but it has nothing to do with ethical stand. Good or bad values could be assigned to conduct, behavior or performance. Attention should, therefore, be given to young children in their first steps of socialization. The individual's inner-self should be taught to adopt, embrace and carryout a set of behaviors that suits to the general stance of the time. Take for example the Capital Punishment case. Beheading was a legitimated punishment in France of the $18^{\text {th }}$ Century. But most of them oppose it when it continued to be used in Arabia Saudi. Capital Punishment is legitimized in some of US states while was abolished in others. Even more moderate issues, like Homosexualism or adultery, accept today much better attention than was allowed just fifty years back. As a symbol representing the spirit of the time, it could be acknowledged that whereas Homogeneity represents the Modernity of the past the $20^{\text {th }}$ Century, heterogeneity represents the future, the Post-modernism of the future, the $21^{\text {st }}$ Century. Moreover, whereas in the past, equality, in general, was a banner of the less-privileged citizens. At present, in Western Democracies, diversity and multiplicity are the accepted terms for properly describing societies. So now, times change, people change and with them ideas, perceptions and legitimations alter. Good and Bad lose their clear and firm definition and the stage is ready for appearing of new visions and terms. But, unfortunately, it is easier to criticize former systems and regimes, than producing new and fresh guidelines for life. And, additionally, progress comes through permanent strive for exceling, but, not all the former arrangements are bad. Irresponsible and exaggerated freedom, may result with anarchy. Thus, we promote the idea of accepting the smart dynamic equilibrium as the leading motto for resolving future social challenges. The above three expressions express and articulate the spirit, the vision and the inspiration of our proposition for better life. Further, we have to add some words on perils and obstacles endanger future advancement.

\section{The Threats of Mediocrity}

"Unexpressed emotions will never die. They are buried alive and will come forth later in uglier ways." (Sigmund Freud, Quotes)

\subsection{Preview}

Mediocrity became very popular at the third millennium. The computer "Word" Treasures software, addresses mediocrity as "Poorness, Weakness or Averageness." These expressions however, do not cover all the meanings of the term, especially not the less-sympathetic ones. Thus, we have no choice but further discussing more on this topic.

At the nineteenth and twentieth centuries, when the spirit of Modernity took place over the world of knowledge, the structure of personal and social behavior was almost clear. For good or bad, society at that time, was a firm and stable. Civic Organizations, beside Clergy and Aristocracy, were categorized, by working classes, professional guilds and different trading associations. At that time, 
most people have known and have accepted their social status and complied with the prevailing social order. In short, this was a society of belonging. Every individual had exactly known his/her social place and status.

Four major processes and occurrences, which took place along the $20^{\text {th }}$ Century, changed the stiff structure of the Modern societies. These processes also had hastened the move toward the Post-modern era:

First was, the Public Schooling system that, within relatively short time, made education mandatory and available to all.

The second factor that has shaken the rigid social order was the accumulated effect of two World Wars. They were significant game-changers that brought together millions, while declaring that all people are alike in their wishes, hopes and sorrows.

The third factor was the fast and substantive technological advancement, which occurred during the second half of the $20^{\text {th }}$ Century. This significant technological development acquaints millions with many communications, transportation and other technologies while opening new horizons and hopes for them. Fourth was the significant growth of High education and the permanent effort of availing it to the general public. This effort resulted with extending higher education, made it affordable for millions.

In the eve of the third millennium millions of free and curious people wait now for a miracle to happen and improve their life. One miraculous matter happened, by the introduction of the smartphones and their varied derivatives. The world most popular communication device came in and became the prevalent tool for data collection and knowledge acquiring.

Thus, at the opening of the $21^{\text {st }}$ Century, all over the world, people are better educated, more equipped for acquiring knowledge and capable to develop inspiring hopes.

Two important phenomena evolved at that time and grew to become very significant systems through the coming years. The first one was the Social Media a set of social networks that enables individuals to communicate anonymously. The second phenomenon was the setting up of the Internet. The use of Smartphones enabled many to be familiar with the largest source of news, data and learning materials, always available and everywhere. Google and Wikipedia became the new-era's Electronic Libraries. Only few would have guessed at the beginning, how popular and important these networks will become for the general public. However, at present, nobody can run civilized life without using these two communication networks.

Years ago, when completing my master degree, I met the Goals' of Learning issue, regarding Baccalaureate studies. For getting an authentic view of the official Modern perspective, I had asked friends at the British National Foundation for Education, to cite me the British major Goals of education. They quote me three:

(a) Qualifying the learner for promotion at the work-place,

(b) Preparing oneself for higher education (M.A., $\mathrm{PhD}$ ) and 
(c) Pursuing intellectual growth needs.

A short review done at the same time, indicated that the BA students agreed with this assumption. $40 \%$ of them chose the first (a) goal, another $40 \%$ chose the second goal (b) and only $20 \%$ have chosen the third goal (c). This type of goals presentation and the students' responding pattern, clearly supported the argument that in the Classical Modern era, high education was mostly directed toward social elite groups. Our brief review indicated that in the past, most students really wanted to learn, in according with this presumption (Amos, 1990).

At the $21^{\text {st }}$ Century, when high education, at least B.A. studies, became very popular, another fourth category of learning Goal (d), should be added. This fourth learning Goal, is linked and strong connected with the disorderly behave and messy life, many experienced at the chaotic Post-modern time of today. The fourth Goal (d), therefore, should reflect positive and negative, thru and false public and social pressures and demands.

Previous studies assume that at the future, no more than $20 \%-25 \%$ of the students' population, will choose "pursuing intellectual growth needs", goal (c), as the main reason for joining University. The remaining 75 - 80 percent would be divided by three. Assigning 25\% - 30\% to every of the three goals (a), (b) and (d). So, now, when students would be asked to categorize their choosing, it seems that the distribution will be in accordance with the above percentage. One quarter of the students will study in order to be "qualified for promotion" at the work-place, goal (a) the second quarter will be studying for "promoting academic career" goal (b), while the last quarter will study because of different and other unclear reasons or social pressures goal (d). It is fair to assume that, in general, the above division of students by their learning goals, is still relevant at present, despite the growth of the learning population. Thus, although millions of people seek higher education, only one quarter of them, really is in search of knowledge and Wisdom. It is so, because Wisdom is a very rare and hard-get product, demanding serious investment of time, energy and devotion. As a clear supposition from this fact comes the assumption that nations that will succeed in gathering the above required resources, will produce the proper conditions and will encourage risk-taking and entrepreneurship, undoubtfully will find their way to the top.

Following the processes mentioned, at the early years of the $21^{\text {st }}$ Century, many common people were overflowed by a load of communication's means and social pressure to seek higher education. But the real challenge was and still remains, how to find effective ways for properly and effectively use the new opened rich and remarkable sources for the benefit of both, individuals and societies? How to exploit the new wonderful available opportunities for promoting people and their organizations? The answer to these two questions is apparently simple. Governments, Social organizations and similar Non-Governmental Organizations (NGOs), together with professional guilds, talented and able individuals, should create joint ventures and find ways for collaboration and cooperation. 


\subsection{What Mediocrity Is?}

"Two things are infinite: the universe and human stupidity;

I am not sure about the universe." (Albert Einstein)

With all respect to Albert Einstein, we add a third phenomenon, Mediocre people, Pretenders and Hypocrites, that always are around, trying to steal the show. Since we see them as a serious social trouble, we extend the discussion on them.

Wikipedia offers the following definitions for Mediocrity, among them are:

- "The quality or state of being just average,

- The state or quality of being mediocre,

- Mediocre ability, achievement or performance,

- Mediocre ability or attainment,

- A person of mediocre abilities or attainments." (Mediocrity Definitions).

These five definitions relate to mediocrity as a value-less or a neutral expression, similar to average, with no any emotional connotations. Our observations, which encouraged us authoring this work, try adding some additional, less-sympathetic aspect to this presentation. We argue that today, at Western societies, mediocrity became a quality that threatens and may endanger many democratic activities. The main difference between ordinary average or moderate people and a mediocre person lays in the fact that the first accept their social status with no special pretensions, whereas the latter conceals, rejects and denies it, because of hidden pretensions. For not to be misunderstood, we have to say it again, loud and clear, nothing is wrong with any social or professional status a person has. The problem lays with the pretension to be something different. On a train, for example, serve an engineer, a conductor and a clerk. Each of them makes his job and is appreciated accordingly. However, when the clerk presents himself as the train engineer, because this is a more prestigious position, this is a pretentious act, typical to behavior of many mediocre people. This difference is also expressed as mediocre people urge to appear as those who know-it-all while pretending that they have the qualities required. This behavior characterizes bad sales-persons, who have quite less-attractive image. Sales-persons are very required individuals in today's consumption-oriented society. However, their approach, ways of talking and sales manners not always fit academic, political and social environments. A bad sales person charges too high price, promises too many good promises and easily pretends to solve all after-sale problems. Some fools still tend to trust them. The erroneous pretension is wrong twice; First, most of them do not belong to the statistical definition they pretend to be. Secondly, they conceal their true status while pretending to be someone higher at the hierarchy. Our claim is quite simple and clear, everyone, should appear in public as he or she are in Life. Never pretend to know something you are not familiar with. Some make-ups are allowed, but not masks, masquerades and other camouflage's means. Leave them for Halloween. 
For deepening our argumentation, we have to go back to some of the statistical presentations. When running again the same analysis on the original Majority group ( $60 \%$ of the total population), a smaller group of about $20 \%$ of the whole population will be diagnosed. They are the average of the average, or the mediocre of the mediocre. Any type of statistical analysis will result with the same outcomes, mediocre rests in the mid of the middling line, as presented by the purple columns in Figure 1.

When exploring human populations by using the "Normal Distribution Theorem" the outcomes indicate that $15 \%-20 \%$ of the educated population, in Western nations, will excel in using the inspiring resources opened for enhancing their knowledge. Another minority of $15 \%-25 \%$ will use the new tools just for social contacts, small talks, chit-chat and gossip. The remaining majority, some $50 \%-60 \%$ of the better educated population, will ordinarily use the new tools for a variety of less-important objectives. When running again the same analysis on the Majority group, a smaller group of about $20 \%-25 \%$ of the whole population will be diagnosed. They are the average of the average, or the mediocre of the mediocre, they become the main source of Mediocrity, see Figure 1. These also are the individuals who attend higher education, due to family and social pressure and the general demand of having a formal academic diploma.

Normal populations, communities or authentic groups of people are composed of different people with different talents and capacities. Most ordinary nations today, are Heterogenous ones. This happens in contrast to the previous preferred model of Modern Homogeneity. This statement is mostly true for the US and for Europe. The true meaning of this statement is that these countries contain a variety of different people, a combination of many individuals who, in their own way, hold a different but original set of values. Consequently, the cultural and the intellectual basis of these nations grew and must change. Additionally, a country's intellectual and cultural potential grows and bloom as much as its citizens varied and achieve higher level of self-actualization. It is almost like a musical orchestra. The quality and the worth of a performing ensemble grew as more musical instruments are involved and participate in the concert. A good conductor can do little with a poor ensemble, while a high qualified group of musicians will manage well even when the conductor is not so good.

Understanding the present nature of many of Western nations is very important point, since erroneously, mediocre politicians frequently loudly claim, that they are the only original representatives of the "We the People" statement. They vehemently argue that they know best what the constituent think, what it looks for, and what is common people's point of view.

We have nothing more to say about those people, but just quoting George Bernard Shaw's opinion on politicians' behavior: "He knows nothing, and he think he knows everything. That points clearly to a political career." (George Bernard Shaw). 


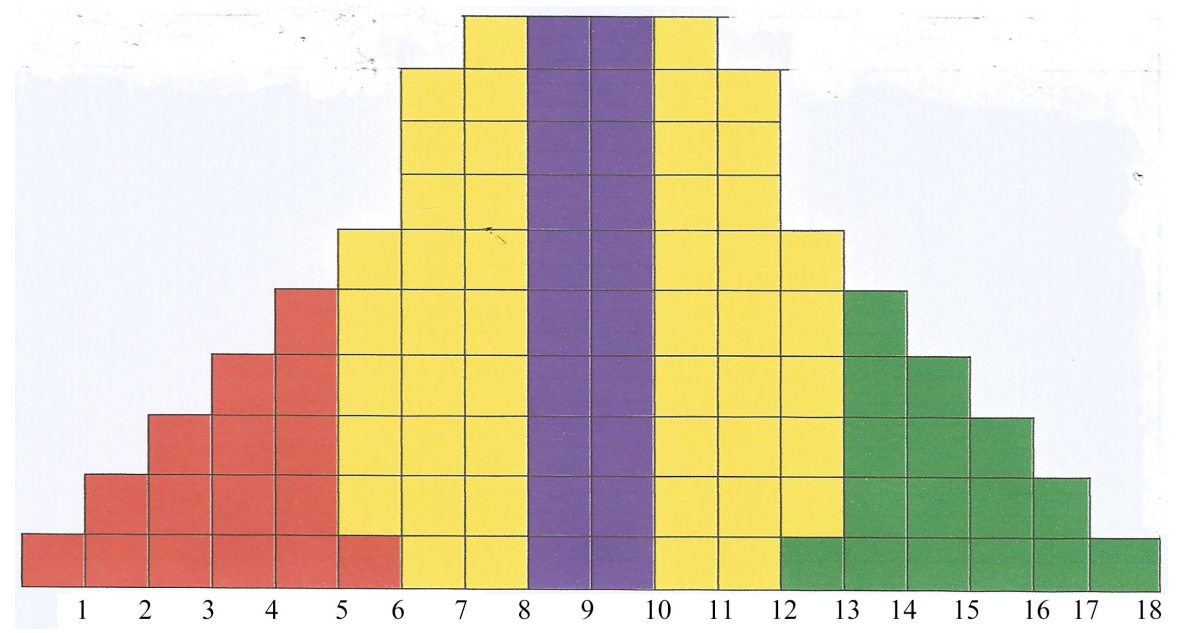

Figure 1. Mediocrity at the Center of a "Normal" Population. 2 variables, 5 Measuring Levels and 5 groups of Results.

This is a common example that shows how, in a democratic state, a noisy and ardent minority could gather political power, gains influence on public opinion and annoys government.

Wikipedia define Mediocracy in a relatively modest way. But at the $21^{\text {st }}$ Century, with reference to recent innovations in the fields of Mass Communication, Media and Smartphones, Mediocrity became more and more dangerous. Mediocrity was presented also in the past, but it was just a simple state of being. At present it becomes a growing political threat since its proponents converted it into a banner. A challenging Flag for the pretenders who like fighting against the existing establishments. It affects many areas of daily life and it became an important factor in public life. The fact that they know that mediocre people are just a minority group, does not make any difference. All over the globe these people knew to convert their concealed inferiority sense into a noisy leverage that helps them to lead political struggles. Many of them have supported the election of former President Donald Trump in US and the Brexit movement in UK.

Additionally, the past twenty years of high education proliferation and the use of Social Media as a leading source of information increases the threat of those pretending people. Whereas fifty years ago, at the $20^{\text {th }}$ Century, most pretenders were less-educated, at present many of them are Universities' or Colleges' graduates. So, "they know little on much, much on little, but eventually, almost nothing." Their pretension is higher, since it "rests" on an academic podium. For their needs they collect trivia, trifles, gossip and innuendos and know well how to convert them into a political power. They do not think or act as the subscribers of the American Constitution, the writers of the British Magna Carta, or the authors of the German Basic Law.

The saying "When Politics Appears Prudence Disappears" seems well describing this situation. 


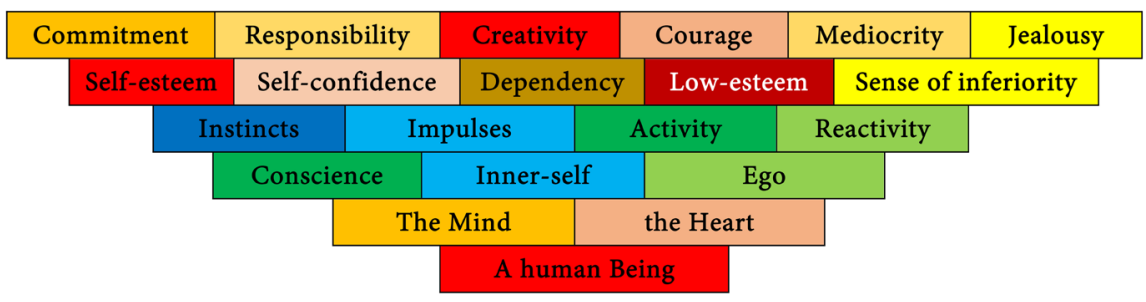

Figure 2. Mediocrity at the highest level of awareness.

When referring to the monetary world, it makes sense to compare mediocre politicians with what is known as New-Rich or the "Show me" individuals. The outstanding difference between these two groups rests on the fact that the "New Rich" just look for public attention, and maybe admiration, whereas mediocre politicians look for influence and power. Whereas the "New Rich" cause no harm, mediocre politicians may cause much tumult, confusion and even disorder.

It makes sense to assume that in most academic and professional fields, in those areas that much time, energy and talent are required, mediocrity is not widely spread. It is more popular among oratory fields, communication, law, sociology and political sciences. Fortunately, or not, most practical professions, those who demand open mind, concrete performing capacity and skilled talented hands, have no extra time for spending on general contemplations, political discourses and soul-searching matters. Because of that reality and because the fact that at present, older smart experienced elderlies are not demanded any more, the stage is free and inviting mediocre individuals to run the show (Figure 2).

\section{Conclusion}

"Out of your vulnerability will come your strength." (Sigmund Freud, Wikipedia)

In order to conclude this worrying essay with an optimistic tone, we cite here a well-known psychologist, Sigmund Freud. This quote supports the Author's optimistic view about on the coming future. However, a realistic approach as presented here helps to improve diagnosing current problems. Moreover, similar to medicine, a thorough and reliable diagnosis indicates on the possible remedy. It also may become leverage for better results.

Exploring the Inner-self and a person's Ego is almost like walking through a mine-field. Many unexpected surprises appear and rarely one can tell whether they are positive or negative. The main point is that human inner-self, like the minuscule world of Atoms or the humongous dimension of the outer space, is still full with mysteries and unknown occurrences. Recognizing and legitimizing the inner-self involvement and its influence on people behavior, are the first step toward understanding. The second step would be following and examining the inner-self impacts on orderly life and better defining the less-known areas. 
Legitimizing the existence of the less-known world is the beginning of marching on the right track. The COVID-19 pandemic demonstrates how short are we vis-à-vis Nature. It clearly indicates that "something wrong is in the Western Civilization."

Mediocrity, on the other hand, well demonstrates the wrong and erroneous directions people may choose for promoting their self-interests.

We conclude by claiming that the Inner-self, Ego and Conscience are the primary originators of the individual's personality. Upon them, lays the burden of crafting and restructuring advanced Post-modern societies. These renewed societies should be composed of human-oriented organizations, which promote Togetherness, Solidarity, Creative Thinking and Social Responsibility. In this way, the reorganized societies would be able to replace the former brutal Capitalism. For enabling a good start and because this challenge weights so much, it is suggested to start teaching indoctrinating it to youngsters from their early years. Finally, it is assumed that by following the above advice wellness and progress will come soon.

\section{Conflicts of Interest}

The author declares no conflicts of interest regarding the publication of this paper.

\section{References}

Albert Einstein Quotes. Wikipedia.

Amos, A. (1990). Expectations and Satisfaction of Former BA-ABS Students. National Louis University: MSc. Management Degree.

George Bernard Shaw Quotes. Wikipedia.

Holy Bible, King James Version, Genesis Chapter 1, 27.

Marx Karl Quotes. Wikipedia.

Mediocrity Definitions. Wikipedia.

Sigmund Freud Quotes. Google Search.

Sigmund Freud Quotes. Quotes.

Sigmund Freud Quotes. Wikipedia. 